\title{
Delayed Lymphedema due to Activated Axillary Lymph Node Dysfunction in a Patient With Breast Cancer
}

\author{
Dong Gyu Lee, MD, PhD \\ Department of Physical Medicine and Rehabilitation, Yeungnam University College of Medicine, Daegu, Korea
}

A 45-year-old woman who underwent a right total mastectomy with axillary lymph node dissection (ALND) visited the rehabilitation department because of lymphedema that developed after the surgery. Histological examination revealed eight positive level I axillary lymph nodes. Thus, radiotherapy was administered to the right side of the breast and supraclavicular areas, including the supraclavicular and axillary fossae, at a radiation dose of 60 Gy.

After the operation and radiotherapy, she was referred to the rehabilitation department owing to mild lymphedema in her right arm with circumference-based differences of $1.1 \mathrm{~cm}$ and $0.5 \mathrm{~cm}$ in the mid-forearm and mid-arm between the upper extremities, respectively. After complete decongestive therapy, which included stretching exercises, manual lymphatic drainage, and elastic compression stockings, the difference in the circumference between the upper extremities was decreased, which led to the resolution of the lymphedema symptoms. At that time, the lymphedema was not severe; hence, compression bandage treatment was not performed. Although the radioactivity on the right side was less than that on the left side, lymphoscintigraphy revealed radioactivity in the axillary lymph nodes. More- over, no dermal backflow was observed. The patient visited an outpatient clinic regularly for follow-up of her condition.

Seventeen months later, her lymphedema suddenly worsened without any specific event. She did not have cellulitis on the affected arm, weight gain, or recurrence of breast cancer. The circumference-based differences in the mid-forearm and mid-arm between the upper extremities were $3.9 \mathrm{~cm}$ and $2.7 \mathrm{~cm}$, respectively [1]. Lymphoscintigraphy was performed again to examine the activities of the axillary lymph nodes, which were well visualized as in the previous examination. However, this time, the right axillary lymph node was not visible, and only the dermal backflow due to the restraining of the lymphatic drainage was seen. Decongestive lymphatic therapy with compressive bandaging was applied to treat the lymphedema. Five sessions of compressive bandaging treatment and manual lymph drainage massage were conducted in the hospital. During the treatment session, the patient was instructed to apply the compression bandage on her own at home. Despite the application of compressive bandaging treatment for 1 year, the lymphedema did not return to its previous state. The circumference-based differences in the mid-forearm and mid-arm

Received March 25, 2020; Revised May 11, 2020; Accepted June 12, 2020; Published online December 31 , 2020

Corresponding author: Dong Gyu Lee

Department of Physical Medicine and Rehabilitation, Yeungnam University College of Medicine, 170 Hyeonchung-ro, Nam-gu, Daegu 42415, Korea. Tel: +82-53-620-3829, Fax: +82-53-624-8356, E-mail: painfree@yu.ac.kr ORCID: Dong Gyu Lee (https://orcid.org/0000-0002-4787-4448).

(c) This is an open-access article distributed under the terms of the Creative Commons Attribution Non-Commercial License (http://creativecommons.org/ licenses/by-nc/4.0) which permits unrestricted noncommercial use, distribution, and reproduction in any medium, provided the original work is properly cited. Copyright (C) 2020 by Korean Academy of Rehabilitation Medicine 


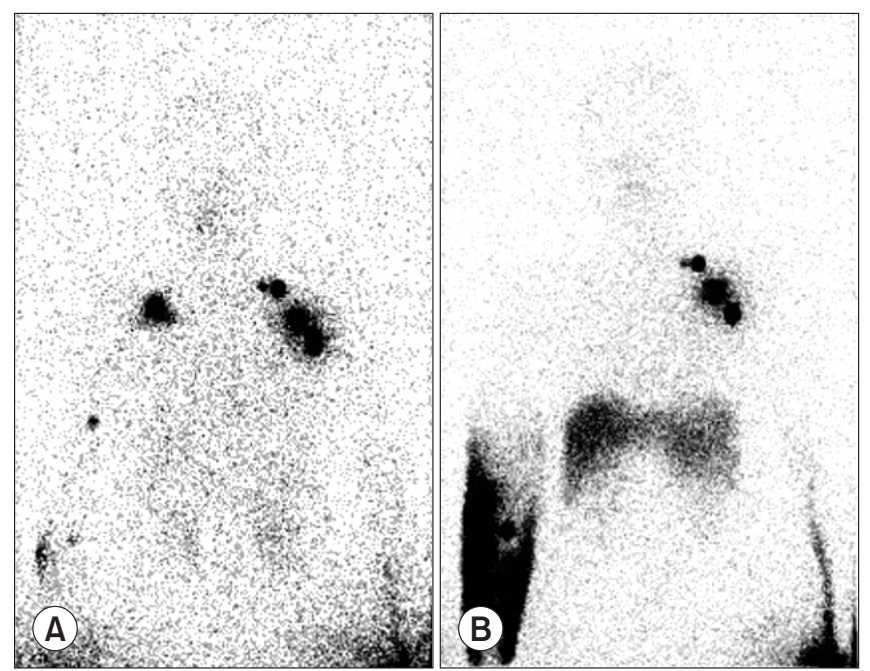

Fig. 1. Anterior-posterior lymphoscintigraphy image of a patient with breast cancer who underwent a right total mastectomy with axillary lymph node dissection. (A) The lymphoscintigram obtained at 2 months after the operation shows lesser radioactivity in the right axillary lymph nodes than that in the left axillary lymph nodes. (B) The lymphoscintigram obtained at 17 months after the operation shows dermal backflow on the right side and no radioactivity in the axillary areas.

between the upper extremities were $3.1 \mathrm{~cm}$ and $1.7 \mathrm{~cm}$, respectively.

The axillary lymph node drains the upper arm lymphatics. Thus, ALND results in interstitial fluid accumulation in the upper extremities. Lymphedema can occur several years after breast cancer surgery [2], and radiotherapy may contribute to delayed lymphedema. Radiotherapy causes lymphatic dysfunction and tissue fibrosis, which decrease lymphatic drainage [3]. The present patient had active axillary lymph nodes after mastectomy with ALND, which maintained lymphatic drainage in the upper extremities. Fig. 1 shows that the dysfunction of the remaining lymph nodes caused the delayed lymphedema in our patient, who survived breast cancer after undergoing ALND.

\section{CONFLICT OF INTEREST}

No potential conflict of interest relevant to this article was reported.

\section{REFERENCES}

1. Chen YW, Tsai HJ, Hung HC, Tsauo JY. Reliability study of measurements for lymphedema in breast cancer patients. Am J Phys Med Rehabil 2008;87:33-8.

2. McDuff SG, Mina AI, Brunelle CL, Salama L, Warren LE, Abouegylah M, et al. Timing of lymphedema after treatment for breast cancer: when are patients most at risk? Int J Radiat Oncol Biol Phys 2019;103:62-70.

3. Avraham T, Yan A, Zampell JC, Daluvoy SV, Haimovitz-Friedman A, Cordeiro AP, et al. Radiation therapy causes loss of dermal lymphatic vessels and interferes with lymphatic function by TGF-betal-mediated tissue fibrosis. Am J Physiol Cell Physiol 2010;299:C589605. 